\title{
43W, 52\% PAE X-Band AlGaN/GaN HEMTs MMIC Amplifiers
}

\author{
S. Piotrowicz ${ }^{\mathrm{I}}$, Z. Ouarch ${ }^{\mathrm{II}}$, E. Chartier ${ }^{\mathrm{I}}$, R. Aubry ${ }^{\mathrm{I}}$, G.Callet ${ }^{\mathrm{I}} \mathrm{III}$, D. Floriot ${ }^{\mathrm{II}}$, J.C.Jacquet ${ }^{\mathrm{I}}$, \\ O. Jardel $^{\mathrm{I}}$, E. Morvan ${ }^{\mathrm{I}}$, T. Reveyrand ${ }^{\mathrm{III}}$, N. Sarazin ${ }^{\mathrm{I}}$, and S.L. Delage ${ }^{\mathrm{I}}$. \\ I : ALCATEL-THALES III-V Lab, Route de Nozay, 91461 Marcoussis, France. \\ II : United Monolithic Semiconductors, Rd. 128, 91401 Orsay, France. \\ III: XLIM, Faculté des sciences de Limoges, 87060 Limoges, France
}

\begin{abstract}
This paper presents the results obtained on XBand GaN MMICs developed in the frame of the Korrigan project launched by the European Defense Agency. GaN has already demonstrated excellent output power levels, nevertheless demonstration of excellent $P A E$ associated to very high power in MMIC technology is still challenging. In this work, we present State-of-the-Art results on AIGaN/GaN MMIC amplifiers. An output power of $43 \mathrm{~W}$ with $52 \%$ of PAE was achieved at $10.5 \mathrm{GHz}$ showing that high power associated with high $\mathrm{PAE}$ can be obtained at X-band using MMIC GaN technology.
\end{abstract} band.

Index Terms - GaN, HEMT, MMIC, power amplifier, X-

\section{INTRODUCTION}

The presence of piezoelectric effects in the GaN material leads to the presence of piezoelectric charges at interfaces, giving a 2-dimensional electron gas with an electron density larger than that created in GaAs HEMTs using intentional doping. The large bandgap of $3.4 \mathrm{eV}$ results in a high breakdown field of $3 \mathrm{MV} / \mathrm{cm}$, the thermal conductivity of $\mathrm{GaN}$ at $300 \mathrm{~K}$ is $190 \mathrm{Wm}^{-1} \mathrm{~K}^{-1}$ and that of $\mathrm{SiC}$ is $400 \mathrm{Wm}^{-1} \mathrm{~K}^{-1}$ allowing a good dissipation of the heat generated in the channel. On the other hand the high breakdown field allows an increase in bias voltage by a factor of at least 5 . These combined characteristics lead to power densities up to a factor of 10 times larger than in GaAs HEMTs [1], [2],[3],[4]. The higher power available in GaN devices means that there is an opportunity to trade power for PAE. In this work, we report on the performances obtained with MMIC power amplifiers at X-band on AlGaN/GaN HEMT technology on $\mathrm{SiC}$ substrate.

\section{DEVICE FABRICATION}

The AlGaN/GaN HEMT epitaxial layer was grown on a silicon carbide substrate by low-pressure metal organic chemical vapor deposition (MOCVD). Electrical isolation of devices was performed by helium implantation. Ti/Al/Ni/Au ohmic contacts were formed using rapid thermal annealing at temperature of $900^{\circ} \mathrm{C}$. Mean contact resistance extracted from TLM measurement is $0.2 \Omega . \mathrm{mm}$. Mo-based T-gates with $0.25 \mu \mathrm{m}$ length were defined by electron beam lithography. The devices were then passivated using plasma enhanced chemical vapor deposition (PECVD) of $\mathrm{SiO} 2 / \mathrm{Si} 3 \mathrm{~N} 4$. After front side processing, the $\mathrm{SiC}$ wafer was thinned down to $100 \mu \mathrm{m}$. Plasma etching via-holes technology was used to ground the devices. Fig.1 shows the gain current cut-off frequency $(\mathrm{Ft})$ and maximum available gain cut-off frequency (Fmag) for various total gate width devices.

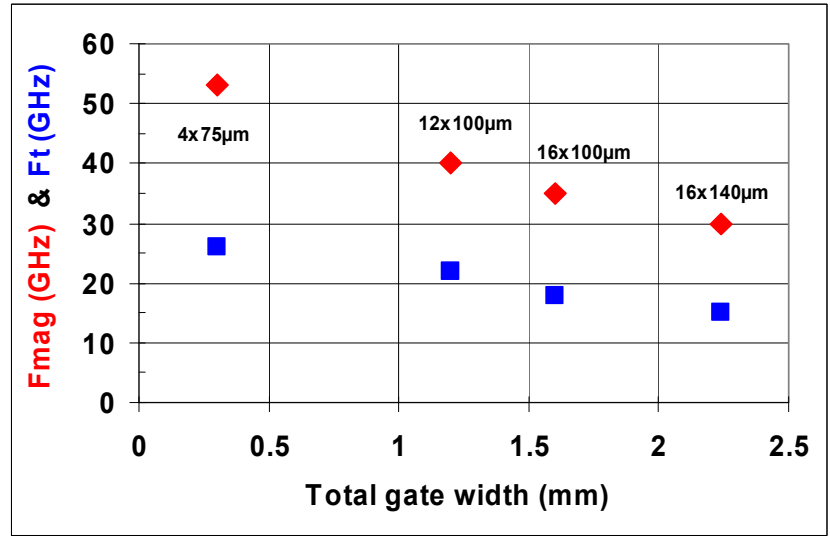

Fig. 1. Fmag and Ft evolution versus total gate width $(\mathrm{Vds}=5 \mathrm{~V}$, $\mathrm{Ids}=100 \mathrm{~mA} / \mathrm{mm}$ )

A typical power device of $1.6 \mathrm{~mm}$ total gate width presents a Ft value of $18 \mathrm{GHz}$ and a Fmag value of $35 \mathrm{GHz}$. A ratio of 2 between $\mathrm{Ft}$ and Fmag values is well conserved from elementary to power devices.

\section{DEVICE TOPOLOGY}

Elementary devices are based on $16 \times 100 \mu \mathrm{m}$ topology. This power device, presented on Fig. 2, is used both in the first and second stage. It has a maximum available gain of $11.8 \mathrm{~dB}$ at $10 \mathrm{GHz}$ and a maximum available gain cut-off 
frequency of $35 \mathrm{GHz}$ at a Vds voltage of $20 \mathrm{~V}$ and $320 \mathrm{~mA}$ of drain current in continuous mode.

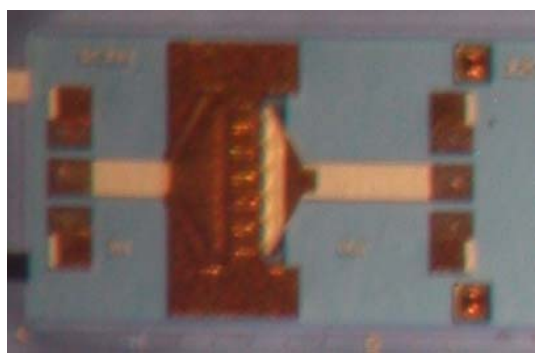

Fig. 2. Photograph of the microstrip $16 \times 100 \mu \mathrm{m}$ power device.

Fig. 3 shows load-pull power measurements of this $1.6 \mathrm{~mm}$ device at $10 \mathrm{GHz}$. Measurements are performed in pulse mode with a pulse length of $10 \mu$ s with $10 \%$ of duty cycle and without any harmonic frequencies optimization. The device is biased at a voltage of $25 \mathrm{~V}$ and a quiescent drain current of $430 \mathrm{~mA}$. At the optimum load at the fundamental frequency for maximum PAE $(5+\mathrm{j} .5 \Omega)$, the device shows a PAE of $55 \%$ with a typical output power of $38 \mathrm{dBm}(6.4 \mathrm{~W})$ corresponding to a power density of $4 \mathrm{~W} / \mathrm{mm}$ and $9.5 \mathrm{~dB}$ of associated gain. The linear gain is $11 \mathrm{~dB}$. At the optimum load at the fundamental frequency for maximum output power $(10-\mathrm{j} .2 \Omega)$, the output power reached $40.6 \mathrm{dBm}$ $(11.4 \mathrm{~W}-7.1 \mathrm{~W} / \mathrm{mm})$ with $51 \%$ of associated PAE and $10 \mathrm{~dB}$ gain. Appropriate harmonic tuning and re-tuned of the fundamental frequency bring the optimal impedances for maximum power and PAE together and thus contribute to increase the output power and PAE of devices in MMIC circuits.

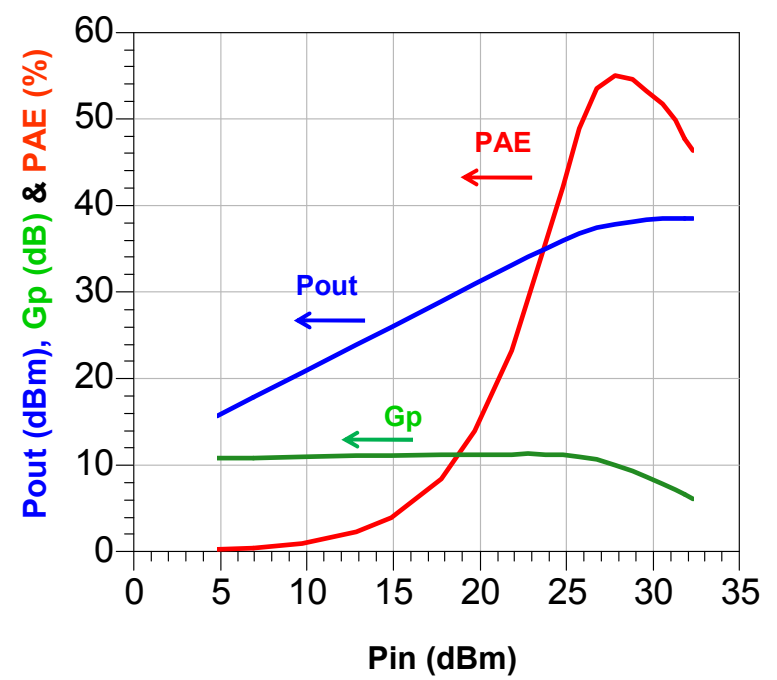

Fig. 3. Load-Pull measurement of $16 \times 100 \mu \mathrm{m}$ device at optimum load for PAE. $\left(\mathrm{Vds}_{0}=25 \mathrm{~V}, \mathrm{Ids}_{0}=430 \mathrm{~mA}, \mathrm{~F}_{0}=10 \mathrm{GHz}\right.$, pulsed $10 \mu \mathrm{s} / 10 \%)$

\section{AMPLIFIER DESIGN}

Amplifier is based on two stages architecture (Fig. 4). Two devices are used in the first stage which drives four transistors in the output stage. The chip size is $4500 \times 4000$ $\mu \mathrm{m}^{2}\left(18 \mathrm{~mm}^{2}\right)$. Due to the high level of output power reached and in order to reduce both DC and RF losses in the transmission lines of matching and biasing networks, electroplated gold layer of $6 \mu \mathrm{m}$ thickness was deposited on the output combiner as well as on the first and on the interstage combiners. A parallel RC network in series at the input of each transistor enhances the stability of HPAs and prevents the occurrence of parametric oscillation phenomena [5]. The simulation of the stability of these amplifiers was first performed in linear operation mode at the quiescent biasing point. Then, the non linear stability was analyzed at high input power level [6].

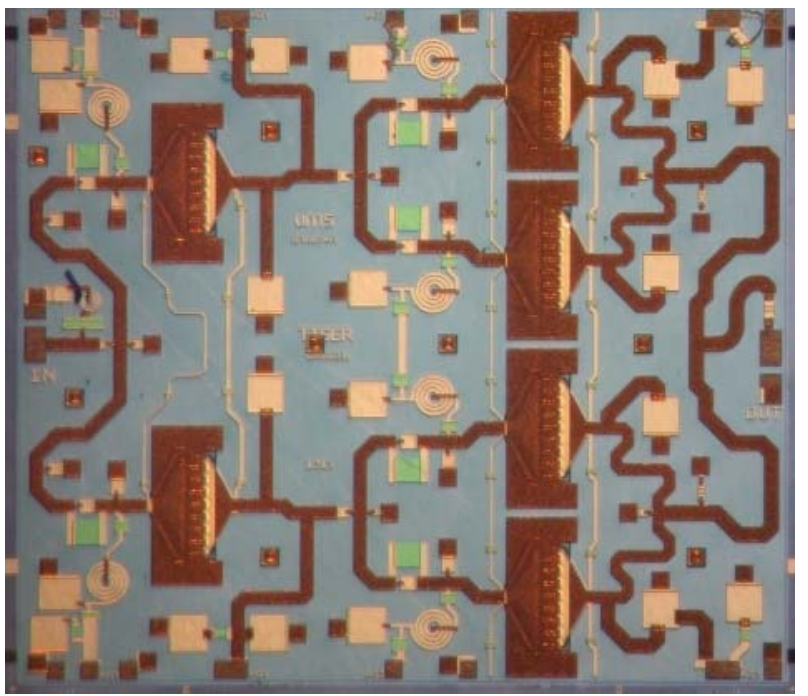

Fig. 4. Photograph of amplifier.

\section{AMPLIFIER RESULTS - BATCH 1}

Different batches of amplifiers were realized. This part presents results obtained in the frame of the first one. Amplifiers were first measured on wafer with a pulsed SParameter bench. Fig. 5 shows S-Parameter measurements of amplifier at reduced drain voltage of $20 \mathrm{~V}$ and drain current of $2 \mathrm{~A}$.

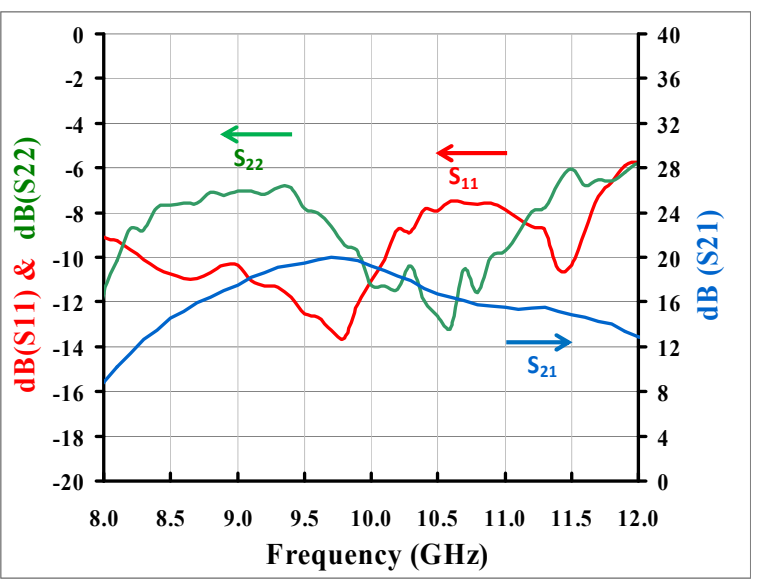

Fig. 5. On wafer pulsed S-parameter measurements of amplifier $\left(\mathrm{Vds}_{0}=20 \mathrm{~V}, \mathrm{Ids}_{0}=2 \mathrm{~A}\right)$. 
$S_{11}$ and $S_{22}$ are better than $-7 \mathrm{~dB}$ in the [8.5-10.5] GHz bandwidth. $\mathrm{S}_{21}$ is better than $14 \mathrm{~dB}$ with a maximum of $20 \mathrm{~dB}$ at $9.8 \mathrm{GHz}$.

Amplifiers were then characterised at large signal input power with drain pulse length of $20 \mu$ s with $10 \%$ of duty cycle. The drain voltage and quiescent current are respectively $25 \mathrm{~V}$ and $2.5 \mathrm{~A}$. Fig. 6 shows the output power, associated gain and PAE of the amplifier over the frequency range of $8.5 \mathrm{GHz}$ to $10.5 \mathrm{GHz}$ at an input power of $32 \mathrm{dBm}$.

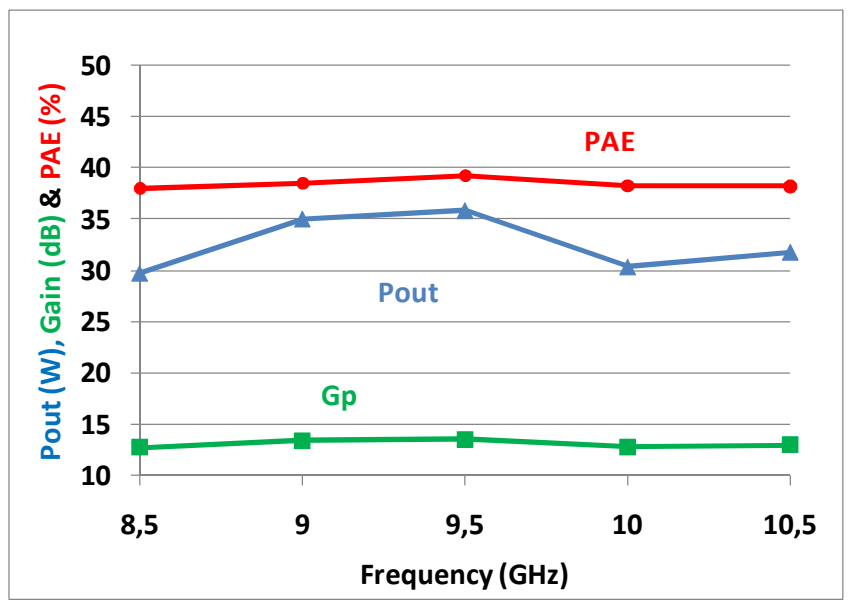

Fig. 6. On wafer measurements of amplifier (batch1) at $32 \mathrm{dBm}$ of input power $\left(\mathrm{Vds}_{0}=25 \mathrm{~V}, \operatorname{Ids}_{0}=2.5 \mathrm{~A}\right)$.

The amplifier delivers a maximum output power of $45.5 \mathrm{dBm}(35.8 \mathrm{~W})$ with $39.5 \%$ of PAE and $13.5 \mathrm{~dB}$ of associated gain at $9.5 \mathrm{GHz}$. Over the $2 \mathrm{GHz}$ bandwidth, the output power is above $30 \mathrm{~W}$ with a very flat PAE between $38 \%$ and $39.5 \%$. The compression level of $4 \mathrm{~dB}$ enables the amplifier to deliver its best PAE. The small signal gain is $17.7 \mathrm{~dB}$ at $9.5 \mathrm{GHz}$.

Amplifiers were then mounted in typical test Jig presented in Fig. 7. The chip is glued directly on the Jig without additional heat spreader.
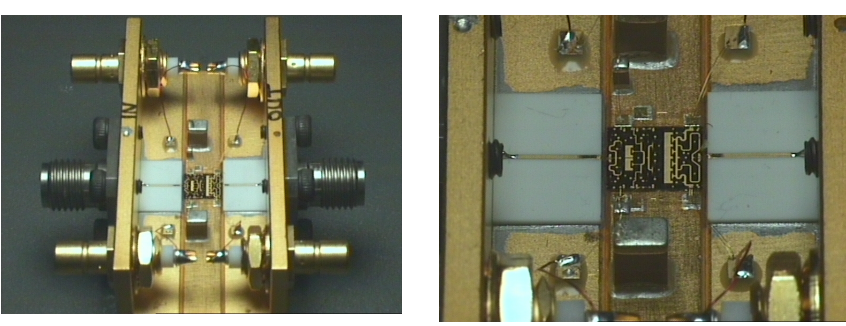

Fig. 7. Typical amplifier mounted in test Jig.

Fig. 8 shows the results for various pulse conditions: short pulse of $5 \mu \mathrm{s}$ length with $10 \%$ of duty cycle and for long pulse condition of $50 \mu$ s length with $20 \%$ of duty cycle.

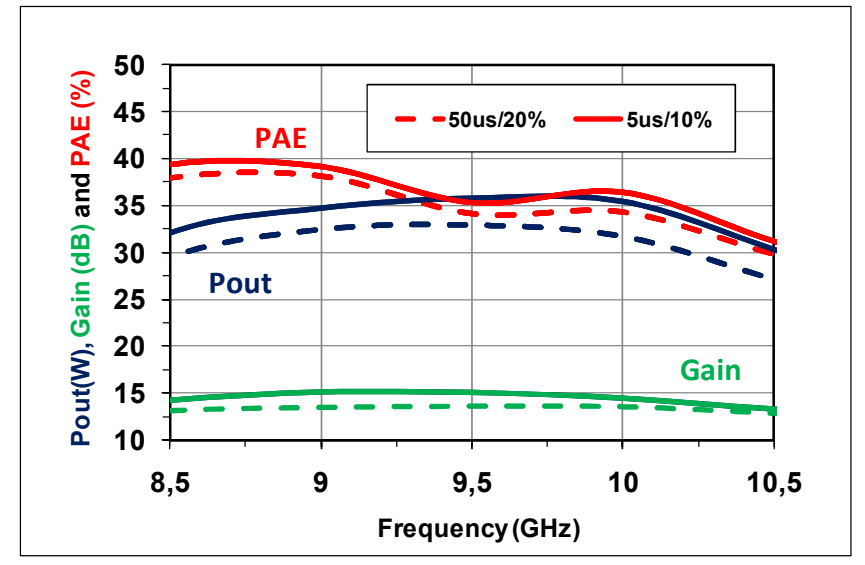

Fig. 8. Output power, Gain and PAE of amplifier in test Jig at input power of $32 \mathrm{dBm}(\mathrm{Vds} 0=25 \mathrm{~V}, \operatorname{Ids} 0=2.3 \mathrm{~A})$ for different pulse conditions.

Between the two pulse conditions the output power decreases by $3 \mathrm{~W}$ in the bandwidth corresponding to around $8 \%$ of power losses. The PAE decreases by around 2 pts. The high level of output power and PAE are well retrieved. The differences of behaviour in the bandwidth can be explained by the use of input and output wire bondings for RF connections.

\section{AMPLIFIER RESULTS - BATCH 2}

A second batch of amplifiers was processed without any design modification. Fig. 9 shows on wafer performances at 10.5 GHz. The amplifier shows $2 \mathrm{~dB}$ more gain than amplifier from batch $n^{\circ} 1$ and power performances slightly shifted towards high frequencies.

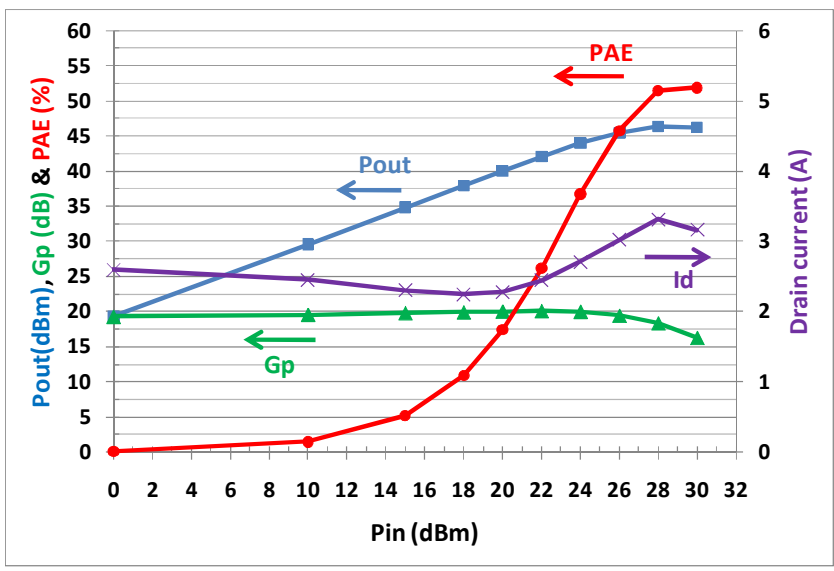

Fig. 9. Gain, Ouput power, PAE and drain current of amplifier (batch2) at $10.5 \mathrm{GHz}$ versus the input power $\left(\mathrm{Vds}_{0}=25 \mathrm{~V}\right.$, $\operatorname{Ids}_{0}=2.2 \mathrm{~A}$, pulsed $20 \mu \mathrm{s} / 10 \%$ ).

The amplifier delivers a maximum output power of $46.3 \mathrm{dBm}(43 \mathrm{~W})$ corresponding to a power density of 6.7 $\mathrm{W} / \mathrm{mm}$ with $52 \%$ of PAE and $16.3 \mathrm{~dB}$ of associated gain. To our knowledge, this result represents State-of-the-Art PAE obtained with X-band GaN MMIC amplifier with over 10W of output power. Fig. 10 shows the power performances measured from $8.5 \mathrm{GHz}$ to $11 \mathrm{GHz}$. 


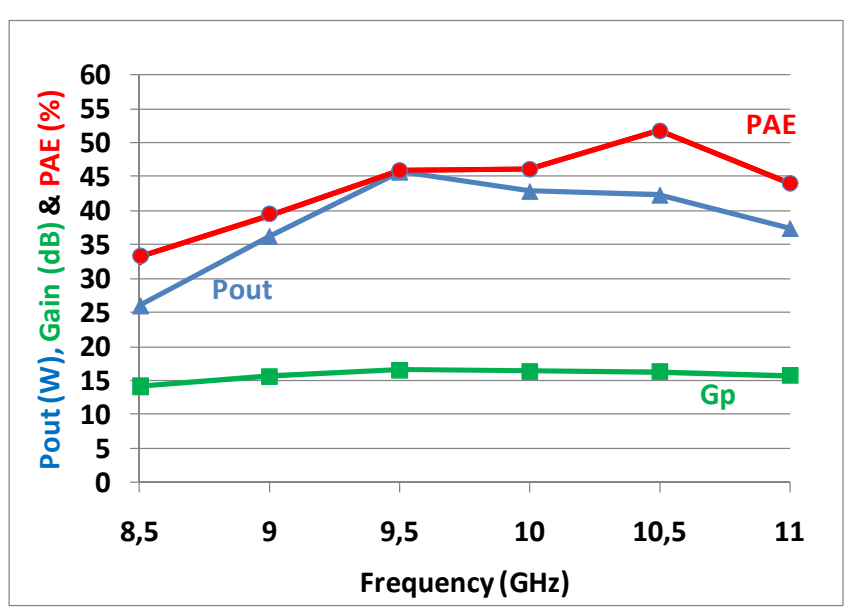

Fig. 10. Gain, Ouput power and PAE of amplifier (batch2) at pin $=30 \mathrm{dBm}\left(\mathrm{Vds}_{0}=25 \mathrm{~V}, \operatorname{Ids}_{0}=2.2 \mathrm{~A}\right.$, pulsed $\left.20 \mu \mathrm{s} / 10 \%\right)$.

The output power is above $35 \mathrm{~W}$ with PAE higher than $40 \%$ on $2 \mathrm{GHz}$ bandwidth. Fig. 11 represents, to our knowledge, the state of the art results of GaN HPA MMIC in $\mathrm{X}$-Band. While many results have been already reported with PAE up to $67 \%$ with lower output power, this paper reports a PAE of $52 \%$ with $43 \mathrm{~W}$ of output power showing that high power and high PAE can be achieved at X-band using GaN technology.

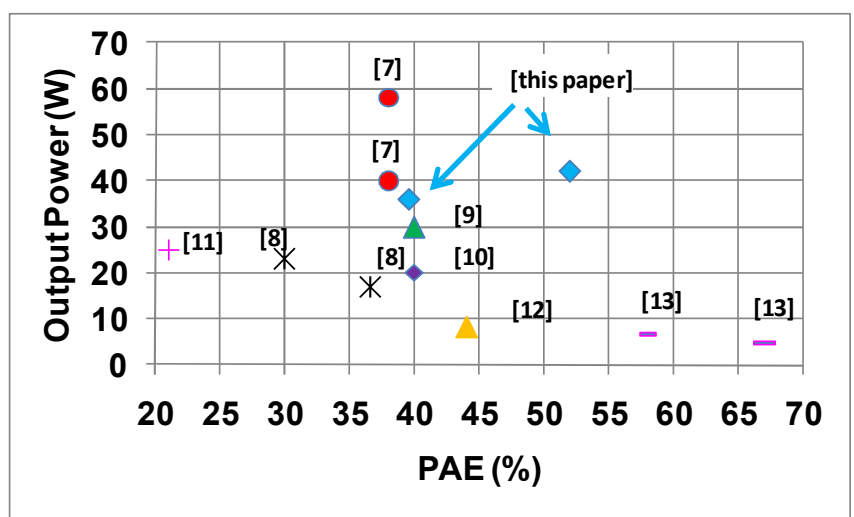

Fig. 11. State-of-the-Art GaN MMIC HPAs in X-Band

\section{CONCLUSIONS}

In this paper we present results obtained on X-band MMIC amplifiers using AlGaN/GaN HEMT $0.25 \mu \mathrm{m}$ gate length technology developed in the frame of the European KORRIGAN contract.

A first batch of $18 \mathrm{~mm}^{2}$ MMIC amplifiers exhibited a maximum output power of $45.5 \mathrm{dBm}(35.8 \mathrm{~W})$ with $39.5 \%$ of PAE and $13.5 \mathrm{~dB}$ of associated gain at $9.5 \mathrm{GHz}$. Over the 2 $\mathrm{GHz}$ bandwidth, the output power is above $30 \mathrm{~W}$ with a very flat PAE between $38 \%$ and $39.5 \%$. On wafer and in test Jig measurements were performed under pulse conditions.

A second batch allows us to obtain State-of-the-Art results: An output power of $43 \mathrm{~W}$ with $52 \%$ of PAE was achieved at a drain bias voltage of $25 \mathrm{~V}$ showing that high power and high PAE can be obtained in X-band using GaN technology. An output power of above $35 \mathrm{~W}$ with PAE higher than $40 \%$ over $2 \mathrm{GHz}$ of bandwidth were measured. This paper demonstrates once again the great interest of $\mathrm{GaN}$ technology for X-band radar applications.

\section{ACKNOWLEDGEMENT}

The authors would like to thank the French MOD and DGA component department under European Defense Agency contract KORRIGAN for their support. They would like also to acknowledge QinetiQ for providing epitaxial structures and Prof. J.Obregon for his constant technical advice.

\section{REFERENCES}

[1] Yi-Feng Wu, D. Kapolnek, J.P. Ibbrtson, P. Parikh, B.P. Kellerand U.K. Mishra. "Very-High power density AlGaN/GaN HEMTs". IEEE Transactions on electronic devices, Vol. 48, $\mathrm{n}^{\circ} 3$, pp.586-590, March 2001 .

[2] S.T. Sheppard et al. "High power microwave GaN/AlGaN HEMT's on SiC substrate",. IEEE Electron Device Letters, Vol. 20, pp.161163, June 1999.

[3] S.Piotrowicz, E.Chartier, J.C.Jacquet, D.Floriot, J.Obregon, P.Dueme, J.Delaire, Y.Mancuso. "Ultra Compact X-Band GaInP/GaAs HBT MMIC amplifiers : $11 \mathrm{~W}, 42 \%$ of PAE on $13 \mathrm{~mm}^{2}$ and $8.7 \mathrm{~W}, 38 \%$ of PAE on 9mm ${ }^{2}$. IEEE MTT-S Digest, June 2006.

[4] A.M. Couturier, S. Heckmann, V. Serru, T. Huet, P. Chaumas, J J. Fontecave, M. Camiade, J.P.Viaud and S. Piotrowicz. "A Robust $11 \mathrm{~W}$ High efficiency X-band GaInP HBT amplifier”. IEEE MTT-S Digest, June 2007.

[5] D.Teeter, A.Platzker and R.Bourque. "A compact network for eliminating parametric oscillations in high power MMIC amplifiers". IEEE MTT-S Digest, pp.967-970, June 1999.

[6] A. Anakabe, S.Mons, T.Gasseling, P. Casas, R. Quéré, J.M. Collantes and A. Malet. "Efficient nonlinear stability analysis of microwave circuits using commercially available tools". European Microwave Week Conference, pages 1017-1020, 2002.

[7] S. Piotrowicz, E. Morvan, R. Aubry, S. Bansropun, T. Bouvet, E. Chartier, T. Dean, O. Drisse, C. Dua, D. Floriot, M.A. diFortePoisson, Y. Gourdel, A.J. Hydes, J.C. Jacquet, O. Jardel, D. Lancereau, J.O. Mc Lean, G. Lecoustre, A. Martin, Z. Ouarch, T. Reveyrand, M. Richard, N. Sarazin, D. Thenot and S.L. Delage. "State of the Art 58W, 38\% PAE X-Band AlGaN/GaN HEMTs microstrip MMIC Amplifiers". CSIC 2008 Conference, Monterey USA.

[8] P. Schuh,R. Leberer,H. Sledzik, M.Oppermann,B.Adelseck,H. Brugger, R.Behtash, H.Leier, R. Quay, R.Kiefer. "20W GaN HPAs for Next Generation X-Band T/R-Modules". IMS 2006 Conference, San Francisco, USA.

[9] C. Costrini, M. Calori, A. Cetronio, C. Lanzieri, S. Lavanga, M. Peroni, E. Limiti, A. Serino, G. Ghione, and G. Melone, “ A 20 Watt Microstrip X Band AlGaN/GaN HPA MMIC for Advanced Radar Applications", EuMW Conference, Amsterdam, 2008.

[10] J. Küuhn, F. van Raay, R. Quay, R. Kiefer, D. Peschel, M. Mikulla, M. Seelmann-Eggebert, W. Bronner, M. Schlechtweg, O. Ambacher, and M. Thumm. "Design of X-Band GaN MMICs Using Field Plates", EuMW Conference, Roma, 2009

[11] D. M. Fanning, L. C. Witkowski, C. Lee, D. C. Dumka, H. Q. Tserng, P. Saunier, W. Gaiewski, E. L. Piner*, K. J. Linthicum* and J. W. Johnson"25 W X-band GaN on Si MMIC", GaAs MANTECH 2005 Conf Proc., New Orleans, USA, April 2005.

[12] H. Klockenhoff, R. Behtash, J. Wurfl, W. Heinrich, and G. Tranckle, "A Compact 16 Watt X-Band GaN-MMIC Power Amplifier," in IEEE MTT-S Digest, 2006, pp. 1846-1849.

[13] R. Tayrani, ' A Spectrally pure 5.0 W, High PAE, (6-12 GHz) GaN Monolithic Class E Power Amplifier for Advanced T/R Modules' RFIC Conference 2007. 